\title{
Use of client-centered virtual reality in rehabilitation after stroke: a feasibility study
}

\author{
Uso da realidade virtual centrada no cliente na reabilitação após acidente vascular \\ encefálico: um estudo de viabilidade
}

\author{
Alberto Luiz ARAMAKI1,5, Rosana Ferreira SAMPAIO², Alessandra CAVALCANT13,4, Fabiana Caetano Martins \\ Silva e DUTRA $1,3,5$
}

\begin{abstract}
Patient-centered virtual reality (VR) programs could assist in the functional recovery of people after a stroke. Objectives: To analyze the feasibility of a rehabilitation protocol using client-centered VR and to evaluate changes in occupational performance and social participation. Methods: This was a mixed methods study. Ten subacute and chronic stroke patients participated in the rehabilitation program using games in non-immersive VR for 40 minutes/day, three days/week, for 12 weeks. Sociodemographic information was collected and the outcome variables included were the Canadian Occupational Performance Measure (COPM) and the Participation Scale. A field diary was used to record the frequency of attendance and adherence of participants and an interview was conducted at the end of program. Results: There were significant and clinically-relevant statistical improvements in the COPM performance score $(p<0.001 ; \mathrm{Cl}=1.29-4.858)$ and in the COPM satisfaction score $(p<0.001 ; C l=1.37-5.124)$, with a difference greater than 4.28 points for performance and 4.58 points for satisfaction. The change in the scores for participation was statistically significant $(p=0.046)$, but there was no clinical improvement $\left(d_{\text {cohen }}=-0.596, C l=-1.862-0.671\right)$. The majority of participants reported more than $75 \%$ consecutive attendance of sessions and there was $100 \%$ adherence to the program. In the interviews, the participants described their post-stroke difficulties; how the video game motivated their engagement in rehabilitation; and the improvement of occupational performance and social participation after participating in the program. Conclusions: VR is a viable tool for the rehabilitation of stroke patients with functional gains, mainly regarding occupational performance and performance satisfaction.
\end{abstract}

Keywords: Rehabilitation; virtual reality exposure therapy; video games; stroke; patient-centered care.

\section{RESUMO}

Programas de realidade virtual (RV) centrados no paciente poderiam auxiliar na recuperação funcional de pessoas após acidente vascular cerebral (AVC). Objetivos: Analisar a viabilidade de um protocolo de reabilitação usando RV centrada no cliente e avaliar mudanças no desempenho ocupacional e na participação social. Métodos: Dez pacientes com AVC participaram do programa de reabilitação utilizando RV por $40 \mathrm{~min} / \mathrm{dia}$, 3 dias/semana, durante 12 semanas. Foram coletadas informações sociodemográficas e as medidas de desfecho incluíram a Medida Canadense de Desempenho Ocupacional (COPM) e a Escala de Participação. Empregou-se um diário para registro da frequência e adesão de cada participante e uma entrevista foi usada para analisar a percepção dos participantes sobre o programa. Resultados: Houve melhora estatisticamente significativa e clinicamente relevante no escore de desempenho da COPM ( $p<0,001 ; \mathrm{IC}=1,219-4,858)$ e no escore de satisfação com o desempenho da COPM ( $p<0,001 ; \mathrm{IC}=1,37$ - 5,154); com diferença maior que 4,28 pontos para o desempenho; e 4,58 pontos para a satisfação. A mudança no escore de participação foi estatisticamente significativa ( $p=0,046)$, mas não houve melhora clínica ( $d_{c o h e n}=-0,596$, IC = -1,862 - 0,671). A maioria dos participantes apresentou mais de $75 \%$ de frequência consecutiva e houve $100 \%$ de adesão ao programa. Nas entrevistas os participantes relataram as dificuldades pós-AVC; como o video game motivou seu engajamento na reabilitação; e a melhora do desempenho ocupacional e da participação social após participar do programa. Conclusões: Os resultados indicam a viabilidade da RV para reabilitação de pacientes com AVC, com ganhos funcionais, principalmente no desempenho ocupacional e satisfação com o desempenho.

Palavras-chave: Reabilitação; terapia de exposição à realidade virtual; jogos de vídeo; acidente vascular cerebral; assistência centrada no paciente.

\footnotetext{
'Universidade Federal do Triângulo Mineiro, Programa de Pós-Graduação em Atenção à Saúde, Uberaba MG, Brasil;

${ }^{2}$ Universidade Federal de Minas Gerais, Programa de Pós-Graduação em Ciências da Reabilitação, Belo Horizonte MG, Brasil;

${ }^{3}$ Universidade Federal do Triângulo Mineiro, Departamento de Terapia Ocupacional, Uberaba MG, Brasil;

¿Universidade Federal do Triângulo Mineiro, Laboratório Integrado de Tecnologia Assistiva (LITA), Uberaba MG, Brasil;

${ }^{5}$ Universidade Federal do Triângulo Mineiro, Núcleo de Estudos e Pesquisas em Trabalho, Participação Social e Saúde (NETRAS), Uberaba MG, Brasil. Alberto Luiz Aramaki iD https://orcid.org/0000-0002-1740-6686; Rosana Ferreira Sampaio (iD https://orcid.org/0000-0002-4775-9650; Alessandra Cavalcanti (iD) https://orcid.org/0000-0002-2306-2031; Fabiana Caetano Martins Silva e Dutra (iD) https://orcid.org/0000-0003-3295-1583
}

Correspondence: Fabiana Caetano Martins Silva e Dutra; Departamento de Terapia Ocupacional, Instituto de Ciências da Saúde, Universidade Federal do Triângulo Mineiro;Av. Getúlio Guaritá, 159, Prédio Administrativo, 4 Piso, Sala 439, Bairro Abadia;38025-440 Uberaba MG, Brasil; E-mail: fabiana.dutra@uftm.edu.br

Support: CNPq (Conselho Nacional de Desenvolvimento Científico e Tecnológico), Brazil.

Conflict of interest: There is no conflict of interest to declare. 
Received 12 March 2019; Received in final form 17 May 2019; Accepted 15 June 2019.

Every year, 16 million people suffer from a stroke, with great economic and social repercussions ${ }^{1}$. In Brazil, this is the leading cause of disability ${ }^{1,2}$. A stroke is a sudden syndrome, characterized by sensory, motor, and cognitive-perceptual alterations ${ }^{1}$. These alterations are associated with disability, limitations in activities of daily life (ADL) and restrictions in social participation, with loss of autonomy and independence $\mathrm{e}^{3,4}$.

Different treatment protocols are used in post-stroke rehabilitation, and consist mainly of motor control approaches, and task oriented training ${ }^{5,6,7}$. Task-based training, mediated by technologies and computerized activities such as virtual reality (VR), has been promising for poststroke patients ${ }^{8,9}$. Virtual reality is a technology for interaction between user and operating system using graphic resources that recreate a virtual environment ${ }^{10}$. One of its advantages is that the environment can be more interesting and pleasant when compared with traditional rehabilitation, increasing motivation, engagement and adherence of patients to the treatment ${ }^{10,11,12}$.

Recent clinical trials with post-stroke patients demonstrated the effectiveness of VR in the rehabilitation of dynamic balance ${ }^{13,14,15,16}$; motor function ${ }^{12,17,18,19,20,21}$; performance and independence in $\mathrm{ADL}^{12,14}$ and quality of life ${ }^{17,19,20,21}$. However, a systematic review found no significant difference in upper limb function when comparing VR with a conventional therapy ${ }^{8}$. Differences between groups were found only when VR was added to the usual treatments ${ }^{8}$. In another review, the VR effects varied from small to moderate for ADL and outcomes for social participation did not change with the intervention'.

Although systematic reviews and meta-analyses on VR effectiveness are growing, they were not conclusive regarding the protocol or intervention parameters, which makes the clinical use of VR difficult ${ }^{8,9,11}$. Higher frequencies of treatment are preferable; however, these findings were not statistically significant ${ }^{8,9}$. Personalized VR protocols that consider a specific patient's requirements seem to offer more benefits. However, it should be noted that these results are also not conclusive and there is no consensus about the issue ${ }^{8,9}$.

As there is little consistency in the literature indicating better VR protocols to be used in clinical practice, it is fundamental to analyze the viability and the patient response potential regarding the intervention using VR. The studies with better quality methodologies evaluated outcomes related to the body structure and function ${ }^{8,9}$. To recommend the therapeutic use of VR in post-stroke patients it is essential to develop patient-centered interventions and focus on assessing performance-related outcomes in activity and participation.

A patient-centered practice is an approach that considers the person's ability to deal with their health condition, to self-manage, to make decisions, to motivate themselves, and adhere to treatment ${ }^{7}$. In this context, this study aimed to analyze the feasibility of a rehabilitation protocol using patient-centered VR and to evaluate changes in occupational performance and social participation of patients after a stroke. The hypothesis was that VR would increase performance, reduce restrictions in participation, and be a viable tool for outpatient intervention with post-stroke patients.

\section{METHODS}

This research was a feasibility study that used mixed methods, including a quantitative and qualitative approach. The quantitative study of the pre- and post-intervention type measured changes in occupational performance and social participation, after a rehabilitation program using VR. The feasibility of the VR was analyzed using qualitative methods. This study was approved by the Institution's Research Ethics Committee.

\section{Local and participants}

The participants were recruited by convenience, at the Rehabilitation Center of the Clinical Hospital of the Federal University of Triângulo Mineiro (HC/UFTM), a public and free rehabilitation service with physical therapy, speech therapy, nutrition, nursing, psychology, and occupational therapy.

We selected participants with primary or recurrent stroke diagnoses, hemiparesis, age 18 or older, of either sex, who were in the rehabilitation program. We excluded participants with strokes older than five years, bilateral hemiparesis, and/or other diseases of the musculoskeletal and central nervous systems, wheelchair users, amputees, visually impaired patients, and those who could not understand or respond to the data collection instruments. The sample was selected from the medical records and by indication of the rehabilitation professionals. A total of 10 patients met the inclusion criteria and agreed to participate in the research.

\section{Evaluation procedures and instruments}

The procedures took place between January and August 2017 at the HC/UFTM Rehabilitation Center and was divided into three sequential phases.

\section{Phase 1: Pre-intervention evaluation}

The participants responded to a socio-demographic questionnaire and were evaluated according to self-reported occupational performance and social participation.

Occupational performance was measured by the Canadian Occupational Performance Measure (COPM). The patients selected the activities that they needed, but which they had not been able to perform, or were not satisfied 
with their performance ${ }^{23}$. The patients assigned a grade of 1-10 to the importance of each activity and selected the five with the most importance. Each activity selected was evaluated for the patient's performance and satisfaction on a scale from 1-10. The total scores were calculated from the means of the performance and satisfaction. Changes in scores greater than two points indicated a clinically relevant improvement ${ }^{23}$.

Social participation was measured by the Participation Scale (P-Scale), version 6.0. The participants would compare themselves with a "peer without disability" and respond to how they perceived their own level of participation compared with the "peer" 24 . The score of any item varied from zero, when the individual did not have restrictions to his participation, to five when the restriction was considered a "big problem". The total score varied from zero to 90 , with smaller values indicating less restriction ${ }^{25}$.

\section{Phase 2: Intervention}

The rehabilitation program using VR was implemented at the HC/UFTM Rehabilitation Center. The literature does not have a standardization of interventions and/or games used in virtual reality programs. Thus, the protocol chosen had the number of sessions and duration following the findings of Aramaki et $\mathrm{al}^{26}$. Therefore, the protocol consisted of three weekly sessions lasting 40 minutes each, developed over 12 weeks, for a total of 36 sessions.

The participants were in an orthostatic position, four meters away from the screen and video game, in a room with natural light. The Xbox $360^{\circ}$ was used with Kinect motion sensor technology.

The games were chosen according to the activities indicated in the COPM as difficult to perform in the initial evaluation. These required training in upper-limb and lower-limb motor skills, motor coordination, and cognitive skills. A detailed description of the information for each game and its main effects are shown in the Figure 1.

The sessions began with the game "20,000 Leaks" to familiarize the participant with the video game interface. Each participant played two or three games for 10 minutes each. In order to avoid fatigue, if necessary, a two-minute interval between games took place.

\section{Phase 3: Post-intervention evaluation and feasibility analysis}

The participants were reassessed using the COPM and P-Scale. The improvement in occupational performance was considered clinically relevant when, besides being statistically significant, it had an increase of two points or more ${ }^{23}$. The decrease in social participation restrictions was considered clinically relevant when it was both statistically significant and showed a $30 \%$ or more reduction, followed the guidelines for feasibility studies ${ }^{27}$.
In the feasibility analysis, a field diary was used to record frequency, adherence and possible dropouts. An individual interview analyzed the participant's perception of the rehabilitation with VR. Five participants with aphasia were interviewed accompanied by a caregiver/relative who helped them provide the information. The interviews were conducted at the HC/UFTM Rehabilitation Center and standardized, following a guide. The guide consisted of questions related to the impact of the stroke on the life of the individuals; previous experience of the participants with video games; how they felt using video games as a form of rehabilitation; and if they noticed changes after the program. The interviews were conducted individually with an average duration of 15 minutes each and were carried out by a researcher, who had no contact with study participants during the intervention period. The interviews were recorded on a voice recorder (Sony ICD-PX312) and transcribed, with the prior authorization of the participants.

\section{Data analysis}

Statistical software IBM SPSS version 20.0 was used for data analysis. Initially, the information was analyzed descriptively. The paired Student's t-test was used to compare the COPM and P-Scale, before and after the intervention. A level of significance of $\alpha=0.05$ and a statistical power of $\beta=0.90$ were considered. Cohen's $d^{28}$ was used to calculate the effect size.

The interviews were subjected to content analysis and followed the stages of pre-analysis, exploration of the material or coding, and treatment of the results obtained/interpretation $^{29}$. The coding the transcripts were carried out by two independent researchers with experience in qualitative studies. The participants' names were replaced by video game characters to preserve their identities.

\section{RESULTS}

In our sample of 10 participants with ages between 21 and 59 years, half were married, and none were working. Nine patients had suffered an ischemic stroke and eight were classified as having had chronic strokes. The complete characteristics of the participants are presented in Table 1.

\section{Self-reported occupational performance and social participation}

The activities described as important and difficult to perform are detailed in Table 2. The self-care domain showed the highest frequency of difficult-to-perform activities (48\%). Activities from the productivity and leisure domains each accounted for $26 \%$ of performance difficulties. All activities are described by domain in Table 3.

The mean of self-reported occupational performance pre-intervention was $2.12(\mathrm{SD}=0.81)$ and the self-reported 

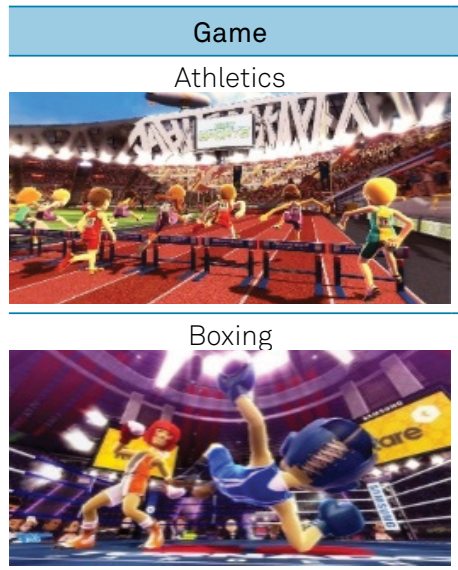

Five events in succession that include: racing (100 meters), dart throwing, disc launching, distance jumping and a hurdle race.
$\mathrm{ROM}^{1}$ of lower limbs to jump and run. Unilateral shoulder and elbow ROM to release the disc and the dart. Abilities of stability, inclining, reaching, gripping, coordination, support, rhythm, and attention.

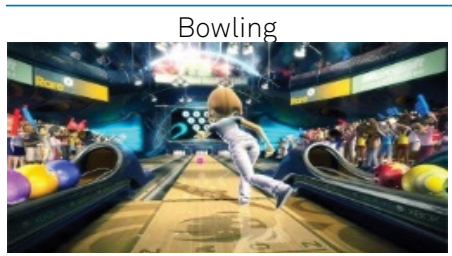

A boxing match in which the player uses his arms to throw punches and defeat the opponent.
Bowling game in which the player must throw the ball forward to knock down the largest number of pins.
Bilateral shoulder and elbow ROM. Fingers held in flexion. Abilities of stability, moving, calibration/ refining, fluidity, resistance, rhythm, focus, attention, and initiative. Upper body dissociation.
Unilateral shoulder, elbow, and fingers ROM. Visuospatial ability. Abilities of stability, positioning, reaching, inclining, gripping, coordination, calibration/refinement, fluidity, focus and attention. Upper body dissociation.

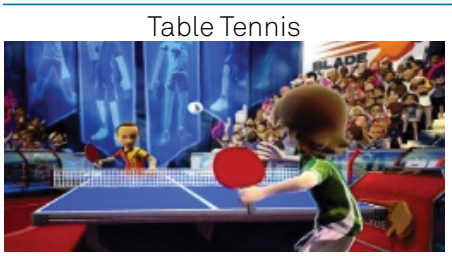

Table tennis game in which the player hits a small ball to the other side of the table using a racket.

Unilateral shoulder and elbow ROM. Abilities of stability, positioning, gripping, coordination, fluidity, rhythm, focus, and attention.

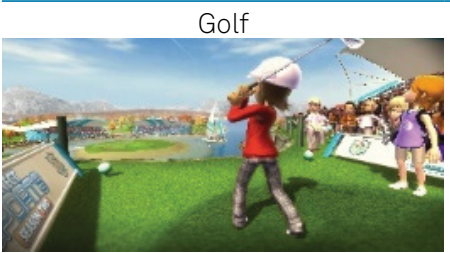

The player must hit the ball with the golf club to place it in the demarcated hole with the red flag.

Lateral rotation of the torso. Bilateral upper-limb ROM. Abilities of aligning, positioning, gripping and coordination, focus and attention.

Tennis

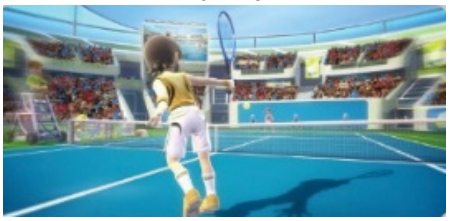

A tennis game in which the player must hit the ball to the other side of the court using a racket.

Unilateral upper-limb ROM. Ability of aligning, gripping, coordination, fluidity, rhythm, and resistance.

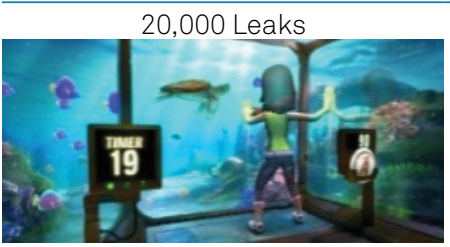

The player is inside an aquarium and must prevent leaks caused by the fish.
Bilateral upper-limb ROM. Hand with splayed fingers. Abilities of stability, positioning, reaching, coordination, fluidity, focus and attention.

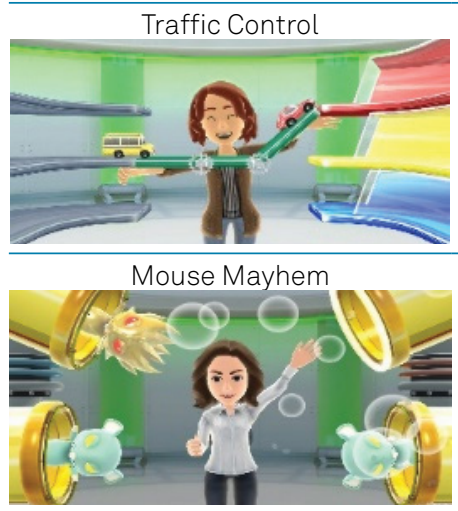

The player uses the arms as bridges to guide the colored vehicles to the road corresponding to their color.
Bilateral upper-limb ROM. Abilities of stability, positioning, coordination, fluidity, rhythm, focus and attention.

ROM: range of motion.

Figure. Detailed description and main effects of the games used in the intervention protocol. 
Table 1. Sociodemographic and clinical characteristics of participants $(n=10)$.

\begin{tabular}{|c|c|c|c|c|c|c|c|c|c|c|}
\hline Variables & $\begin{array}{c}\text { Princess } \\
\text { Zelda }\end{array}$ & Kratos & $\begin{array}{l}\text { Lara } \\
\text { Croft }\end{array}$ & $\begin{array}{l}\text { Solid } \\
\text { Snake }\end{array}$ & Cloud & $\begin{array}{c}\text { Jill } \\
\text { Valentine }\end{array}$ & Sonic & $\begin{array}{l}\text { Super } \\
\text { Mario }\end{array}$ & Ryu & Chun-li \\
\hline Sex & Female & Male & Female & Male & Male & Female & Male & Male & Male & Female \\
\hline Age & 59 & 31 & 36 & 21 & 44 & 38 & 32 & 57 & 38 & 57 \\
\hline $\begin{array}{l}\text { Educational } \\
\text { level }\end{array}$ & $\begin{array}{l}\text { Incomplete } \\
\text { elementary } \\
\text { school }\end{array}$ & $\begin{array}{l}\text { High } \\
\text { school }\end{array}$ & $\begin{array}{l}\text { High } \\
\text { school }\end{array}$ & $\begin{array}{l}\text { Incomplete } \\
\text { high school }\end{array}$ & $\begin{array}{l}\text { Incomplete } \\
\text { higher } \\
\text { education }\end{array}$ & $\begin{array}{l}\text { Incomplete } \\
\text { elementary } \\
\text { school }\end{array}$ & $\begin{array}{l}\text { Incomplete } \\
\text { elementary } \\
\text { school }\end{array}$ & $\begin{array}{c}\text { Elementary } \\
\text { school }\end{array}$ & $\begin{array}{c}\text { Incomplete } \\
\text { elementary } \\
\text { school }\end{array}$ & $\begin{array}{c}\text { Incomplete } \\
\text { elementary } \\
\text { school }\end{array}$ \\
\hline $\begin{array}{l}\text { Professional } \\
\text { ties }\end{array}$ & Retired & $\begin{array}{l}\text { On work } \\
\text { leave }\end{array}$ & $\begin{array}{l}\text { On work } \\
\text { leave }\end{array}$ & Unemployed & Unemployed & $\begin{array}{l}\text { On work } \\
\text { leave }\end{array}$ & $\begin{array}{l}\text { On work } \\
\text { leave }\end{array}$ & $\begin{array}{l}\text { On work } \\
\text { leave }\end{array}$ & Retired & $\begin{array}{l}\text { On work } \\
\text { leave }\end{array}$ \\
\hline Lives with & Partner & Parents & $\begin{array}{l}\text { Parents, } \\
\text { children } \\
\text { and } \\
\text { partner }\end{array}$ & $\begin{array}{c}\text { Parents, } \\
\text { children and } \\
\text { partner }\end{array}$ & $\begin{array}{c}\text { Parents, } \\
\text { children and } \\
\text { partner }\end{array}$ & Children & Alone & $\begin{array}{c}\text { Parents, } \\
\text { children } \\
\text { and partner }\end{array}$ & $\begin{array}{c}\text { Parents, } \\
\text { children } \\
\text { and partner }\end{array}$ & $\begin{array}{c}\text { Parents, } \\
\text { children } \\
\text { and partner }\end{array}$ \\
\hline $\begin{array}{l}\text { Assistance } \\
\text { in the ADL }\end{array}$ & Yes & No & Yes & No & Yes & Yes & Yes & Yes & No & No \\
\hline $\begin{array}{l}\text { Type of } \\
\text { stroke }\end{array}$ & Hemorrhagic & Ischemic & Ischemic & Ischemic & Ischemic & Ischemic & Ischemic & Ischemic & Ischemic & Ischemic \\
\hline $\begin{array}{l}\text { Time since } \\
\text { the stroke }\end{array}$ & 9 months & $\begin{array}{c}24 \\
\text { months }\end{array}$ & $\begin{array}{c}12 \\
\text { months }\end{array}$ & 24 months & 24 months & 2 months & 3 months & 7 months & 12 months & 3 months \\
\hline \multirow{6}{*}{ Games used } & 20,000 Leaks & $\begin{array}{l}20,000 \\
\text { Leaks }\end{array}$ & $\begin{array}{l}20,000 \\
\text { Leaks }\end{array}$ & $\begin{array}{l}20,000 \\
\text { Leaks }\end{array}$ & $\begin{array}{l}20,000 \\
\text { Leaks }\end{array}$ & $\begin{array}{l}20,000 \\
\text { Leaks }\end{array}$ & $\begin{array}{l}20,000 \\
\text { Leaks }\end{array}$ & $\begin{array}{l}20,000 \\
\text { Leaks }\end{array}$ & $\begin{array}{l}20,000 \\
\text { Leaks }\end{array}$ & $\begin{array}{l}20,000 \\
\text { Leaks }\end{array}$ \\
\hline & Boxing & Bowling & Bowling & Boxing & Bowling & Bowling & Bowling & Bowling & Boxing & Boxing \\
\hline & Bowling & $\begin{array}{l}\text { Track and } \\
\text { Field }\end{array}$ & Golf & Bowling & Golf & Golf & Golf & Golf & Bowling & Bowling \\
\hline & Golf & $\begin{array}{l}\text { Traffic } \\
\text { Control }\end{array}$ & Tennis & Table Tennis & Tennis & Tennis & Tennis & Table Tennis & Golf & Golf \\
\hline & Table Tennis & $\begin{array}{l}\text { Mouse } \\
\text { Mayhem }\end{array}$ & & Tennis & & & & Tennis & Table Tennis & TableTennis \\
\hline & Tennis & & & & & & & & Tennis & Tennis \\
\hline
\end{tabular}

Table 2. Description of the activities identified in the COPM by each participant as most important and difficult to perform ( $\mathrm{n=10}$ ).

\begin{tabular}{lccccc}
\hline Participant & Activity 1 & Activity 2 & Activity 3 & Activity 4 & Activity 5 \\
\hline $\begin{array}{l}\text { Princess Zelda } \\
\text { Kratos }\end{array}$ & Changing clothes & Eating & Making a meal & Washing clothes & Taking a bath \\
Lara Croft & Playing the violin & Riding a bike & Talking & Visiting friends & Traveling \\
Solid Snake & Taking a bath & Making a meal & Walking & Changing clothes & Eating \\
Cloud & Writing & Playing football & $\begin{array}{c}\text { Following school } \\
\text { subjects }\end{array}$ & Reading & Using the computer \\
Jill Valentine & Changing clothes & Financial activities & Taking a bath & Using transportation & Traveling \\
Sonic & Tying hair & Shopping & Talking & Cleaning the house & Visiting friends \\
Super Mario & Playing football & Making a meal & Shaving & Changing clothes & Running \\
Ryu & Changing clothes & Taking a bath & Walking & Shopping & Work activities \\
Chun-Li & Changing clothes & Eating & Putting food on the & Taking Walks & Picking up objects at \\
\hline
\end{tabular}

satisfaction mean was $1.64(\mathrm{SD}=0.88)$. After the intervention, the means of the performance and satisfaction were, respectively, $6.40(\mathrm{SD}=1.82)$ and $6.22(\mathrm{SD}=1.78)($ Table 4$)$. The comparison of the COPM performance and satisfaction scores showed a significant increase $(\mathrm{p}<0.001)$, with a difference greater than 4.28 for performance; and 4.58 for satisfaction. The size of the treatment effect was high for performance and satisfaction, $\mathrm{d}_{\text {cohen }}=3.038(\mathrm{CI}=1.219$ to $4.858)$ and $\mathrm{d}_{\text {cohen }}=3.262(\mathrm{CI}=1.37$ to 5.154$)$, respectively. This indicated a statistically-significant and clinically-relevant improvement in both occupational performance and selfreported satisfaction.

The P-Scale scores varied from 14-85 before intervention (mean = 42.10; $\mathrm{SD}=26.42$ ). After the intervention, the restriction average was 31.80 (SD = 28.29), ranging from 0-75 (Table 4). The comparison of the P-Scale scores at both times was statistically significant $(p=0.046)$. However, the effect size of the treatment on social participation was not 
Table 3. Description of the most difficult activities to be carried out reported by participants, divided by COPM domain ( $\mathrm{n}=10$ ).

\begin{tabular}{|c|c|c|c|}
\hline COPM domain & COPM category & Activity & Absolute frequency \\
\hline \multirow{11}{*}{ Self-care } & \multirow{6}{*}{ Personal care } & Getting dressed & 6 \\
\hline & & Taking a bath & 4 \\
\hline & & Eating & 3 \\
\hline & & Shaving & 2 \\
\hline & & Hair brushing/grooming & 1 \\
\hline & & Putting on sneakers & 1 \\
\hline & \multirow{5}{*}{ Independence away from home } & Walking & 2 \\
\hline & & Shopping & 2 \\
\hline & & Financial activities & 1 \\
\hline & & Using public transport & 1 \\
\hline & & Riding a bike & 1 \\
\hline \multirow{11}{*}{ Productivity } & \multirow{2}{*}{ Work } & Work activities & 1 \\
\hline & & Picking up objects at work & 1 \\
\hline & \multirow{5}{*}{ Domestic tasks } & Making a meal & 3 \\
\hline & & Washing clothes & 1 \\
\hline & & Cleaning the house & 1 \\
\hline & & Washing glasses & 1 \\
\hline & & Putting food on the plate & 1 \\
\hline & \multirow{4}{*}{ School } & Writing & 1 \\
\hline & & Following school subjects & 1 \\
\hline & & Reading & 1 \\
\hline & & Using the computer & 1 \\
\hline \multirow{6}{*}{ Leisure } & \multirow[t]{2}{*}{ Quiet recreation } & --- & --- \\
\hline & & Playing football & 3 \\
\hline & \multirow[t]{2}{*}{ Active recreation } & Traveling & 1 \\
\hline & & Playing the violin & 1 \\
\hline & \multirow{2}{*}{ Socialization } & Talking & 3 \\
\hline & & Visiting & 2 \\
\hline
\end{tabular}

Table 4. Comparison of performance and satisfaction averages, evaluated by COPM in pre- and post-intervention periods.

\begin{tabular}{|c|c|c|c|c|c|}
\hline Outcome & Mean (SD) & $p$-value & Sampling power & $\mathrm{d}_{\text {Cohen }}$ & $d_{\text {cohen }}$ confidence interval \\
\hline COPM pre-test performance & $2.12(0.81)$ & \multirow{2}{*}{0.000} & \multirow{2}{*}{$99 \%$} & \multirow{2}{*}{3.038} & \multirow{2}{*}{$1.219-4.858$} \\
\hline COPM post-test performance & $6.40(1.82)$ & & & & \\
\hline COPM pre-test satisfaction & $1.64(0.88)$ & \multirow{2}{*}{0.000} & \multirow{2}{*}{$99 \%$} & \multirow{2}{*}{3.262} & \multirow{2}{*}{$1.37-5.154$} \\
\hline COPM post-test satisfaction & $6.22(1.78)$ & & & & \\
\hline P-Scale pre-test & $42.10(26.42)$ & \multirow{2}{*}{0.046} & \multirow{2}{*}{$59.96 \%$} & \multirow{2}{*}{-0.596} & \multirow{2}{*}{-1.862 to 0.671} \\
\hline P-Scale post-test & $31.80(28.29)$ & & & & \\
\hline
\end{tabular}

significant $\left(\mathrm{d}_{\text {cohen }}=-0.596, \mathrm{CI}=-1.862\right.$ to 0.671$)$ and the change between the scores was $24.4 \%$, lower than that established for viability studies.

\section{Perception of the participants about the intervention}

Ten participants started the protocol, and all completed the 36 sessions of the intervention, with a total of $100 \%$ adherence.
Seven participants showed more than $75 \%$ consecutive attendance of sessions. The main reasons for missing the sessions were unforeseen circumstances of the accompanying persons or with the transport. All missing sessions were replaced, in order to complete the sessions planned in the protocol and offer all the proposed interventions to the participants.

Based on the content of the interviews, significant themes were grouped into three thematic categories: (1) losses and 
difficulties post stroke; (2) the use of video games in rehabilitation; and (3) improvement in occupational performance and social participation.

Regarding post-stroke losses and difficulties, the participants reported changes in daily life and loss of independence and autonomy. They described what had changed in their lives, especially in relation to ADL and household chores:

"I was having trouble bathing, eating and speaking too, (...) my hand could not hold things and they fell easily from my hands." (Chun- $L i$ ).

"My hand got bad, I couldn't hold things. It was hard at school, in the course I'm doing." (Solid Snake).

Patients also reported loss of identity, work, social relations, and social participation. Some participants reported feelings of uselessness and of being seen, by the family and society, as having less value.

"It changed, I don't feel so confident (...), I do not have confidence to travel as I traveled." (Chun-Li).

"Stops working! It ends with our self-esteem. You're not the same person anymore. You're missing a piece." (Super Mario).

The use of video games in rehabilitation provided different sensations to participants and motivation was a factor that influenced engagement ${ }^{2}$. Most of the respondents were unaware of the use of video games as a rehabilitation tool. They considered the invitation to participate in the program as an opportunity to improve.

"I wanted to keep playing and learning more. I liked it a lot...it was motivating." (Solid Snake).

"It was really good...I told my mother that this place was being very good to me." (Ryu).

The participants also said that VR should be part of the treatment of other people and suggested that VR be incorporated into the rehabilitation services:

"Because I was rehabilitated and I think other people will feel good too." (Princess Zelda).

"The video game can do the same thing for other people. Because, thank God, this really makes it better. It's not a lie, it's a good thing!" $(R y u)$.

In view of the results, the participants reported that the video game helped in the rehabilitation and in improvements of occupational performance and social participation ${ }^{3}$.
"I thought it got much better... I'll wash my own clothes. I'm twisting cloth with both hands. Moving my hands more." (Princess Zelda).

"I couldn't touch the computer mouse and now I can do everything. I can even button my pants, write (...) I improved a lot." (Solid Snake).

\section{DISCUSSION}

The sample in this study showed characteristics similar to the literature on stroke patients, with a predominance of men and increased prevalence in the later decades among adults ${ }^{1,2}$.

Among the post-stroke patients, almost half need assistance with $\mathrm{ADL}$ and have restrictions in social participation ${ }^{30}$. In this study, similar results were found. The participants needed help in $\mathrm{ADL}$, with limitations in self-care and chores fundamental to maintaining health and well-being ${ }^{31}$. These limitations were reiterated during the interview and corroborated other studies that have described difficulties after stroke in eating, bathing, dressing, lying down, and getting up ${ }^{32,33}$. The COPM scores also confirmed similar results found in different studies ${ }^{32,33}$.

In productivity, household tasks were the most cited as difficult to perform. These contribute socially and/or economically in the life of the individual, providing support for the person and his/her family members ${ }^{31}$. Mobility and use of public transportation have also been identified as compromised areas. Other investigations with similar populations corroborate these data ${ }^{32,33}$. The limitation of moving throughout the community, and of using transportation, prevents access to the different social environments ${ }^{31}$.

The leisure domain identified more frequent difficulties in active recreation and socialization. The results of the P-Scale and the interviews confirmed these social restrictions. Another study carried out with people with disabilities attending rehabilitation services in Brazil found a similar percentage of restrictions in this outcome ${ }^{25}$. Social participation is associated with the interrelationship of occupations to support the desired involvement in community and family activities, in addition to activities involving peers and friends ${ }^{34}$.

The satisfaction score followed a pattern similar to the performance score, and the interviews reaffirmed the participants' dissatisfaction with their functioning. This score relates to the patients' perception of their health condition, which interferes with their satisfaction. The patientcentered practice enables a therapist to consider the satisfaction, desires and goals of each patient ${ }^{22}$. Thus, the use of patient-centered VR can promote the motivation of patients, improve the sense of self-effectiveness and their satisfaction. These effects highlight the importance of structuring clientcentered rehabilitation, favoring a greater adherence to the intervention and satisfaction with the results. 
After intervention, an improvement was observed in all parameters: performance, satisfaction and social participation. The change in the COPM scores was significant and greater than two points, demonstrating statistical and clinical improvement ${ }^{23}$. The qualitative data confirmed this improvement in the $\mathrm{ADL}$. These findings showed that VR in stroke rehabilitation could lead to functional gains, especially in chronic patients.

Pre- and post-test results and the interview also indicated a change in participation scores. However, the effect size was not significant and the change between the scores was below $30 \%$. Different factors are indicated as barriers to social participation $^{3,4,25}$. Therefore, the restrictions in participation should not be analyzed from a single therapeutic approach, but rather, they should involve proposals that encompass the dynamic interactions between the individual and their environment ${ }^{35}$. Thus, these results suggest that, in the therapeutic process, professionals should also introduce actions directed at the demands of the context in which the individual lives.

The literature on VR in patients with strokes have shown gains and improvements in different measurement parameters $^{12,15-21}$. However, the outcomes of these studies focused on motor components and physical aspects. Few investigations have evaluated the impact of VR on occupational performance and social participation. In addition, some studies indirectly measured performance in activities and social participation $^{13,14,36}$. As recommended by the World Health Organization ${ }^{37}$, it is important to evaluate each functional component independently. Among the clinical trials already published, few evaluated self-care activities ${ }^{14,36}$ and quality of life $e^{17,19}$ as main outcomes in interventions using VR. In this sense, our study adds important results to the literature on the feasibility of VR, with outcomes seldom explored in other investigations.

Adherence to the protocol was $100 \%$ and the majority of participants attended to more than $75 \%$ of the sessions consecutively, higher results than those found in other studies on the feasibility of $\mathrm{VR}^{10,38}$. The VR offered an opportunity for the active engagement of patients in the treatment, favoring a patient-centered practice. Although it does not replace real experiences and specific task training, VR increases customer engagement in the rehabilitation and adherence to treatment ${ }^{6,10}$. This increased engagement was highlighted in the interviews and the VR was described as a resource that provided motivation for rehabilitation.

Regarding the protocol, the VR allowed individualized choices and a gradation of the games according to the activities reported in the COPM. Individualized interventions are a challenge that professionals and rehabilitation services must face, even if they include techniques and resources that are not yet well explored, such as VR. There are no published protocol recommendations for the use of VR in rehabilitation with game descriptions, number of repetitions, duration and number of sessions. Thus, the protocol of this study had a more conservative proposal than those in other investigations that used VR. Our protocol required patients to participate in three sessions per week, which compromised the potential increase in the sample. However, the high level of satisfaction of participants after the intervention, the $100 \%$ adherence and lack of adverse events, reiterated the feasibility of VR in outpatient interventions with patients after a stroke and the applicability of VR in public rehabilitation services. The qualitative data showed how the participants reacted to the intervention and highlighted the patients' satisfaction after the rehabilitation program using VR.

Sample size and convenience selection are limitations to be considered; however, the clinical and sociodemographic characteristics of the sample resembled those of other investigations. The sample also showed a statistical power capable of identifying significant changes in outcomes. These results are important mainly when observing the sample power and the effect size for the occupational performance variable. In addition, the pairing of the observations was a strategy that reduced the variability of the measures, increasing the comparability of individuals.

The changes demonstrate the positive impact of VR on reducing the limitations of people after stroke. The results support the feasibility of the protocol and its potential to improve occupational performance. The qualitative data revealed appreciation of the intervention, engagement in rehabilitation, and an improvement in the performance of activities of daily life. These results encourage the performance of randomized clinical trials with a larger number of participants, and suggest that VR has the potential to become a useful intervention for outpatient rehabilitation of patients after stroke.

\section{Acknowledgments}

The authors thank the Rehabilitation Center for the authorization to carry out the research; and patients for their voluntary participation in this study. Financial support for this study was provided by Brazilian government agencies, including the State of Minas Gerais Research Foundation (FAPEMIG) and the National Council for Scientific and Technological Development (CAPES).

\section{References}

1. Feigin $\mathrm{VL}$, Forouzanfar $\mathrm{MH}$, Krishnamurthi R,

Mensah GA, Connor M, Bennett DA, et al. Global and regional burden of stroke during 1990-2010: findings from the Global Burden of Disease

Study 2010. Lancet. 2014 Jan;383(9913):245-54.

https://doi.org/10.1016/S0140-6736(13)61953-4 
2. Ministério da Saúde (BR). Informações de saúde TABNETEstatísticas vitais. Datasus. 2018 [Cited 2019 jan 19]. Available from: http://tabnet.datasus.gov.br

3. Silva SM, Corrêa JC, Pereira GS, Corrêa FI. Social participation following a stroke: an assessment in accordance with the international classification of functioning, disability and health. Disabil Rehabil. 2019 Apr;41(80):879-86. https://doi.org/10.1080/09638288.2017.1413428

4. Faria-Fortini I, Basílio ML, Scianni AA, Faria CD, Teixeira-Salmela LF. Performance and capacity-based measures of locomotion, compared to impairment-based measures, best predicted participation in individuals with hemiparesis due to stroke. Disabil Rehabil. $2018 \mathrm{Jul} ; 40(15): 1791-8$. https://doi.org/10.1080/09638288.2017.1312570

5. Winstein CJ, Stein J, Arena R, Bates B, Cherney LR, Cramer SC, et al. Guidelines for adult stroke rehabilitation and recovery: a guideline for healthcare professionals from the American Heart Association/American Stroke Association. Stroke. 2016 Jun;47(6):e98-169. https://doi.org/10.1161/STR.0000000000000098

6. Burke JW, McNeill MD, Charles DK, Morrow PJ, Crosbie JH, McDonough SM. Optimising engagement for stroke rehabilitation using serious games. Vis Comput. 2009;25(12):1085-99. https://doi.org/10.1007/s00371-009-0387-4

7. Kristensen HK, Tistad M, Koch L, Ytterberg C. The importance of patient involvement in stroke rehabilitation. PLoS One. 2016 Jun;11(6):e0157149. https://doi.org/10.1371/journal.pone.0157149

8. Laver KE, Lange B, George S, Deutsch JE, Saposnik G, Crotty M. Virtual reality for stroke rehabilitation. Cochrane Database Syst Rev. 2017 Nov;11:CD008349. https://doi.org/10.1002/14651858.CD008349.pub4

9. Aminov A, Rogers JM, Middleton S, Caeyenberghs K, Wilson PH. What do randomized controlled trials say about virtual rehabilitation in stroke? A systematic literature review and meta-analysis of upper-limb and cognitive outcomes. J Neuroeng Rehabil. 2018 Mar;15(1):29. https://doi.org/10.1186/s12984-018-0370-2

10. Levin MF, Snir O, Liebermann DG, Weingarden H, Weiss PL. Virtual reality versus conventional treatment of reaching ability in chronic stroke: clinical feasibility study. Neurol Ther. 2012 Aug;1(1):3. https://doi.org/10.1007/s40120-012-0003-9

11. Laver KE, George S, Thomas S, Deutsch JE, Crotty M. Virtual reality for stroke rehabilitation. Cochrane Database Syst Rev. 2011 Sep;7(9):CD008349. http://doi.org/10.1002/14651858. CD008349.pub2

12. Lee $\mathrm{KH}$. Effects of a virtual reality-based exercise program on functional recovery in stroke patients: part 1.J Phys Ther Sci. 2015 Jun;27(6):1637-40. https://doi.org/10.1589/jpts.27.1637

13. Cho KH, Lee KJ, Song $\mathrm{CH}$. Virtual-reality balance training with a video-game system improves dynamic balance in chronic stroke patients. Tohoku J Exp Med. 2012 Sep;228(1):69-74. https://doi.org/10.1620/tjem.228.69

14. Morone G, Tramontano M, Iosa M, Shofany J, lemma A, Musicco M, et al. The efficacy of balance training with video game-based therapy in subacute stroke patients: a randomized controlled trial. Biomed Res Int. 2014; 2014:ID 580861. https://doi.org/10.1155/2014/580861

15. Lee MM, Shin DC, Song $\mathrm{CH}$. Canoe game-based virtual reality training to improve trunk postural stability, balance, and upper limb motor function in subacute stroke patients: a randomized controlled pilot study. J Phys Ther Sci. 2016 Jul;28(7):2019-24. https://doi.org/10.1589/jpts.28.2019

16. Lee HC, Huang $\mathrm{CL}, \mathrm{Ho} \mathrm{SH}$, Sung WH. The effect of a virtual reality game intervention on balance for patients with stroke: a randomized controlled trial. Games Health J. 2017 Oct;6(5):303-11. https://doi.org/10.1089/g4h.2016.0109
17. Ribeiro NMS, Ferraz DD, Pedreira E, Pinheiro I, Pinto ACS, Neto MG, et al. Virtual rehabilitation via Nintendo Wii ${ }^{\circledR}$ and conventional physical therapy effectively treat post-stroke hemiparetic patients. Top Stroke Rehabil. 2015 Aug;22(4):299-305. https://doi.org/10.1179/1074935714Z.0000000017

18. $\operatorname{Sin} \mathrm{H}$, Lee $\mathrm{G}$. Additional virtual reality training using Xbox Kinect in stroke survivors with hemiplegia. Am J Phys Med Rehabil. 2013 Oct;92(10):871-80. https://doi.org/10.1097/PHM.0b013e3182a38e40

19. Viana RT, Laurentino GE, Souza RJ, Fonseca JB, Silva Filho EM, Dias SN, et al. Effects of the addition of transcranial direct current stimulation to virtual reality therapy after stroke: a pilot randomized controlled trial. NeuroRehabilitation. 2014;34(3):437-46. https://doi.org/10.3233/NRE-141065

20. Carregosa AA, Aguiar Dos Santos LR, Masruha MR, Coêlho ML, Machado TC, Souza DC, et al. Virtual rehabilitation through Nintendo WII in poststroke patients: follow-up. J Stroke Cerebrovasc Dis. 2018 Feb;27(2):494-8. https://doi.org/10.1016/j.jstrokecerebrovasdis.2017.09.029

21. Gonçalves MG, Piva MF, Marques CL, Costa RD, Bazan R, Luvizutto GJ, et al. Effects of virtual reality therapy on upper limb function after stroke and the role of neuroimaging as a predictor of a better response. Arq Neuropsiquiatr. 2018 Oct;76(10):654-62. https://doi.org/10.1590/0004-282×20180104

22. Vaz DV, Jubilini LG, Queiroz LC. Client-centered practice in rehabilitation: definition, instruments and challenges. Rev Ter Ocup Univ Sao Paulo. 2017;28(1):122-7. https://doi.org/10.11606/issn.2238-6149.v28i1p122-127

23. Law M, Cardoso AA, Magalhães LV, Magalhães LC. Medida Canadense de Desempenho Ocupacional (COPM). Belo Horizonte: Editora UFMG; 2009.

24. Brakel WH, Anderson AM, Mutatkar RK, Bakirtzief Z, Nicholls PG, Raju MS, et al. The participation scale: measuring a key concept in public health. Disabil Rehabil. 2006 Feb;28(4):193-203. https://doi.org/10.1080/09638280500192785

25. Silva FC, Sampaio RF, Ferreira FR, Camargos VP, Neves JA. Influence of context in social participation of people with disabilities in Brazil. Rev Panam Salud Publica. 2013 Oct;34(4):250-6.

26. Aramaki AL, Sampaio RF, Reis AC, Cavalcanti A, Dutra FC. Virtual reality in the rehabilitation of patients with stroke: an integrative review. Arq Neuropsiquiatr. 2019 May;77(4):268-78. https://doi.org/10.1590/0004-282×20190025

27. Zylowska L, Ackerman DL, Yang MH, Futrell JL, Horton NL, Hale TS, et al. Mindfulness meditation training in adults and adolescents with ADHD: a feasibility study. J Atten Disord. 2008 May;11(6):737-46. https://doi.org/10.1177/1087054707308502

28. Cohen J.Statistical power analysis for the behavioral sciences. 2nd ed. Hillsdale (NJ): Erlbaum; 1988.

29. Bardin L. Análise de conteúdo. Lisboa: Edições 70; 2011.

30. McKevitt C, Fudge N, Redfern J, Sheldenkar A, Crichton S, Rudd AR, et al. Self-reported long-term needs after stroke. Stroke. 2011 May;42(5):1398-403. https://doi.org/10.1161/STROKEAHA.110.598839

31. American Occupational Therapy Association. Occupational therapy practice framework: Domain and process ( $3 \mathrm{rd}$ ed). Am J Occupat Ther, 2014 68(supl.1):S1-48.

32. Mildner AR, Ponte AS, Delboni MC, Pommerehn J, Estivalet K, Duarte BS. Desempenho ocupacional de pessoas hemiplégicas pós-AVC a partir do uso de tecnologias assistivas. Revisbrato. 2017;1(4):447-56.

33. Meneses KV, Duarte JS, Alencar VO, Pereira AC. [Occupational performance and satisfaction of individuals after cerebral vascular accident]. Cad Ter Ocup UFSCar. 2014;22(3):515-20. Portuguese. https://doi.org/10.4322/cto.2014.072

34. Chang FH, Coster WJ. Conceptualizing the construct of participation in adults with disabilities. Arch Phys Med Rehabil. 2014 Sep;95(9):1791-8. https://doi.org/10.1016/j.apmr.2014.05.008 
35. Dutra FC, Mancini MC, Neves JA, Kirkwood RN, Sampaio RF. Empirical analysis of the International Classification of Functioning, Disability and Health (ICF) using structural equation modeling. Braz J Phys Ther. 2016 Jun;20(5):384-94. https://doi.org/10.1590/bjpt-rbf.2014.0168

36. Singh DK, Mohd Nordin NA, Abd Aziz NA, Lim BK, Soh LC. Effects of substituting a portion of standard physiotherapy time with virtual reality games among community-dwelling stroke survivors. BMC Neurol. 2013 Dec;13(1):199. https://doi.org/10.1186/1471-2377-13-199
37. Organização Mundial da Saúde. CIF: Classificação Internacional de Funcionalidade, Incapacidade e Saúde. São Paulo: EDUSP; 2003.

38. Kim J, Lee M, Kim Y, Seon-Deok E. BumChul Y. Feasibility of an individually tailored virtual reality program for improving upper motor functions and activities of daily living in chronic stroke survivors: a case series. Eur J Integr Med. 2016;8(5):731-7. https://doi.org/10.1016/j.eujim.2016.05.001 